\title{
Gross and histopathological findings in Cercopithecus aethiops with experimental Cyclospora infection in Kenya
}

This article was published in the following Dove Press journal:

Pathology and Laboratory Medicine International

9 May 2012

Number of times this article has been viewed

\section{Purity N Nguhiu' \\ Claire N Wamae ${ }^{2,3}$ \\ Japheth K Magambo 4 \\ Paul G Mbuthia ${ }^{5}$ \\ Daniel C Chai ${ }^{6}$ \\ Dorcas S Yole ${ }^{6}$}

'Department of Veterinary Services, Kabete, Ministry of Livestock

Development, Nairobi, ${ }^{2}$ Directorate of Research and Development, Kenya Methodist University, Meru, ${ }^{3}$ Kenya

Medical Research Institute, Nairobi,

${ }^{4}$ Meru University College of Science and Technology, Meru, ${ }^{5}$ Department of Veterinary Pathology, Microbiology and Parasitology, University of Nairobi, ${ }^{6}$ Department of Tropical Infectious Diseases, Institute of Primate Research, Karen, Nairobi, Kenya
Correspondence: Purity Nguhiu PO Box 76033-00508, Nairobi, Kenya Tel +254 7 227377II

Email puritynguhiu@gmail.com
Abstract: In 2009, experimental Cyclospora infections were established in two juvenile female and two adult male Cercopithecus aethiops (African green monkeys) at Nairobi's Institute of Primate Research (IPR). The study animals were humanely sacrificed, and gross and histopathological evaluation was done at seven weeks post-infection. On gross examination, the juveniles had no abnormalities except for a slight enlargement of the mesenteric lymph nodes, while the adults displayed more pathology of enlarged lymph nodes, hemorrhagic gastrointestinal tracts, widespread necrotic foci of the liver, and enlarged spleens. Significant histopathological findings were observed in both the juveniles and adults, which ranged from mild inflammatory reactions in the stomach and intestines to intense cellular infiltrations with mitotic activity and lymphocytic infiltrations around the periportal area of the livers. The lymph nodes had extensive hyperplasia with many mitotic cells.

Keywords: Cyclospora spp., cyclosporiasis, nonhuman primates, pathological findings, histopathological findings, African green monkeys

\section{Introduction}

Cyclospora cayetanensis ( $C$. cayetanensis) is a protozoan gastrointestinal parasite that affects humans worldwide. C. cayetanensis transmission in developed countries is through food- and water-borne outbreaks, but the transmission and risk factors in endemic tropical countries are poorly understood. ${ }^{1-6}$ The parasite is increasingly being identified in fecal smears of immunocompromised persons with or without international travel histories, ${ }^{7,8}$ as well as in patients with human immunodeficiency virus (HIV) infections or acquired immunodeficiency syndrome. ${ }^{9}$ The parasite has been reported in many geographical regions, but seems to be endemic in tropical countries. $^{5,10-14}$

The epidemiology of cyclosporiasis due to C. cayetanensis is not very clear, with the coccidian protozoa being incapable of direct fecal-oral transmission, and with no known zoonotic reservoir. ${ }^{4}$ C. cayetanensis infection occurs only in humans, with no known animal reservoirs, and attempts to establish experimental infections in laboratory animals have been unsuccessful thus far. ${ }^{15,16}$ Isolation of $C$. cayetanensis in poultry has been reported by García-López. ${ }^{17}$ In the Neinava Governorate in Iraq, C. cayetanensis has been isolated from buffalo (Bubalus bubalus) feces and milk, with only Lugol's iodine and Ziehl-Neelsen's staining methods ${ }^{18}$ reported; no polymerase chain reactions were done.

Cyclospora papionis and Cyclospora cercopitheci have been described, respectively, in olive baboons and African green monkeys (AGMs) from Tanzania, Ethiopia, 
and Kenya. ${ }^{19-21}$ Cyclospora infections have also been reported in nonhuman primates in Sri Lanka. ${ }^{22}$ The nonhuman primate-derived Cyclospora oocysts and human-associated Cyclospora species are morphologically similar, but there was no cross-infection between the different species. ${ }^{19-21}$ A majority of the Cyclospora infections in the nonhuman primates were asymptomatic. ${ }^{19,21}$

After ingestion, Cyclospora oocysts exist in the gastrointestinal tract and invade small bowel epithelia, where they undergo asexual division followed by sexual division to produce mature oocysts that are shed in the host's stool. ${ }^{23}$ Grossly, moderate to severe erythematic mucosa of the distal duodenum is observed in patients with Cyclospora infection. ${ }^{24}$ Distal duodenal and jejunal aspirates of patients with Cyclospora infections had the following histopathological findings: (1) acute and chronic inflammation, (2) reactive hyperemia with vascular dilatation and villous capillary congestion, (3) parasitophorous vacuoles containing both asexual and sexual forms, (4) crypt hyperplasia, (5) epithelial disarray, and (6) partial villous atrophy.,25,26 Intracellular particles similar to sporozoites have been demonstrated in electron micrographs. ${ }^{25}$

C. cayetanensis infections have been associated with the onset of various extraintestinal complications that may accompany prolonged infection, especially in HIVimmunocompromised patients. These infections include (1) acalculous cholecystitis, (2) biliary disease, (3) GuillainBarre syndrome, and (4) reactive arthritis. ${ }^{27-30}$ One case of $C$. cayetanensis oocysts in the sputum of a 60-year-old HIV-negative male with a history of successfully treated tuberculosis (TB) was reported in Argentina. ${ }^{31}$ A similar case was reported in Egypt, where a 45-year-old HIV-negative male with TB history presented oocysts in his sputum in an active TB reaction. ${ }^{32}$
The objective of the current study was to evaluate the gross and histopathological findings of experimental Cyclospora infections in AGMs in the intestine and the extraintestinal involvement of Cyclospora.

\section{Materials and methods}

The Sheather's sugar floatation procedure was used for harvesting Cyclospora oocysts from positive fecal samples. ${ }^{33}$ The oocysts were washed into a clean $15 \mathrm{~mL}$ centrifuge tube using saline solution; $50 \mu \mathrm{L}$ of the solution was used to make a smear, and the number of oocysts on the slide was counted under a microscope at $400 \times$ magnification. Two female juvenile and two adult male AGMs were used in this study. Cyclospora-negative AGMs were purposefully selected based on the availability of Cyclospora-negative animals for inoculation experiments with Cyclospora oocysts. The animals were anesthetized using ketamine and xylazine, and inoculation was done by the introduction of 1000 Cyclospora oocysts into the stomach using a catheter. Physical examination was carried out in the anesthetized animals and their body weight recorded. Daily clinical observations were carried out and any changes in animal behavior, demeanor, lack of appetite, and fecal character were noted during the seven-week experiment period.

The experimentally infected AGMs were humanely put to sleep using ketamine (Ketaset ${ }^{\circledR}$; Fort Dodge Laboratories, Fort Dodge, IA) at $10 \mathrm{mg} / \mathrm{kg}$, and euthanized with $60 \mathrm{mg} / \mathrm{kg}$ body weight of pentobarbitone sodium $200 \mathrm{mg} / \mathrm{mL}\left(\right.$ Sagatal $^{\mathbb{}}$; May and Baker Ltd, Dagenham, UK). Postmortem, gross pathological lesions were noted and recorded. The tissues collected for histological examination came from the liver, stomach, small intestine (jejunum), and lymph nodes (mesenteric and inguinal). The tissues were fixed in $10 \%$ formalin, sectioned into $1-2 \mathrm{~mm}$ pieces, and dehydrated

Table I Gross pathological findings in the four Cercopithecus aethiops (African green monkeys) with experimental Cyclospora infections studied at the Institute of Primate Research

\begin{tabular}{|c|c|c|c|c|c|c|}
\hline \multirow[t]{2}{*}{ AnimID } & \multicolumn{2}{|c|}{ Weight in kg } & \multirow[t]{2}{*}{ Stomach } & \multirow[t]{2}{*}{ Intestines } & \multirow[t]{2}{*}{ Lymph nodes } & \multirow[t]{2}{*}{ Liver } \\
\hline & At $\mathrm{Cl}$ & At PM & & & & \\
\hline Ver I974 F/J & 1.8 & 1.9 & NAD & NAD & $\begin{array}{l}\text { Mesenteric slightly } \\
\text { enlarged }\end{array}$ & NAD \\
\hline Ver 2009 F/J & 1.7 & 1.9 & NAD & NAD & NAD & NAD \\
\hline Ver 2065 M/A & 6.2 & 5.9 & Hemorrhages & $\begin{array}{l}\text { Hemorrhagic mucosal surface, } \\
\text { which was focal but spread } \\
\text { along the whole intestine }\end{array}$ & $\begin{array}{l}\text { Prominent and mildly } \\
\text { enlarged }\end{array}$ & $\begin{array}{l}\text { Widespread mild to moderate } \\
\text { pitting of the surface }\end{array}$ \\
\hline Ver 2092 M/A & 4.1 & 4.4 & NAD & $\begin{array}{l}\text { Wall moderately thickened } \\
\text { and rough }\end{array}$ & $\begin{array}{l}\text { Mesenteric lymph } \\
\text { nodes mildly enlarged }\end{array}$ & $\begin{array}{l}\text { Moderate focal necrotic foci } \\
\text { about I mm in diameter spread } \\
\text { all over the liver surface }\end{array}$ \\
\hline
\end{tabular}

Abbreviations: AnimID, animal identification number of the four experimental Cyclospora-inoculated study animals, comprised of two female juvenile and two male adult African green monkeys; Ver, Vervet monkey; F, female; M, male; A, adult; J, juvenile; CI, Cyclospora inoculation; PM, postmortem; NAD, no abnormality detected. 

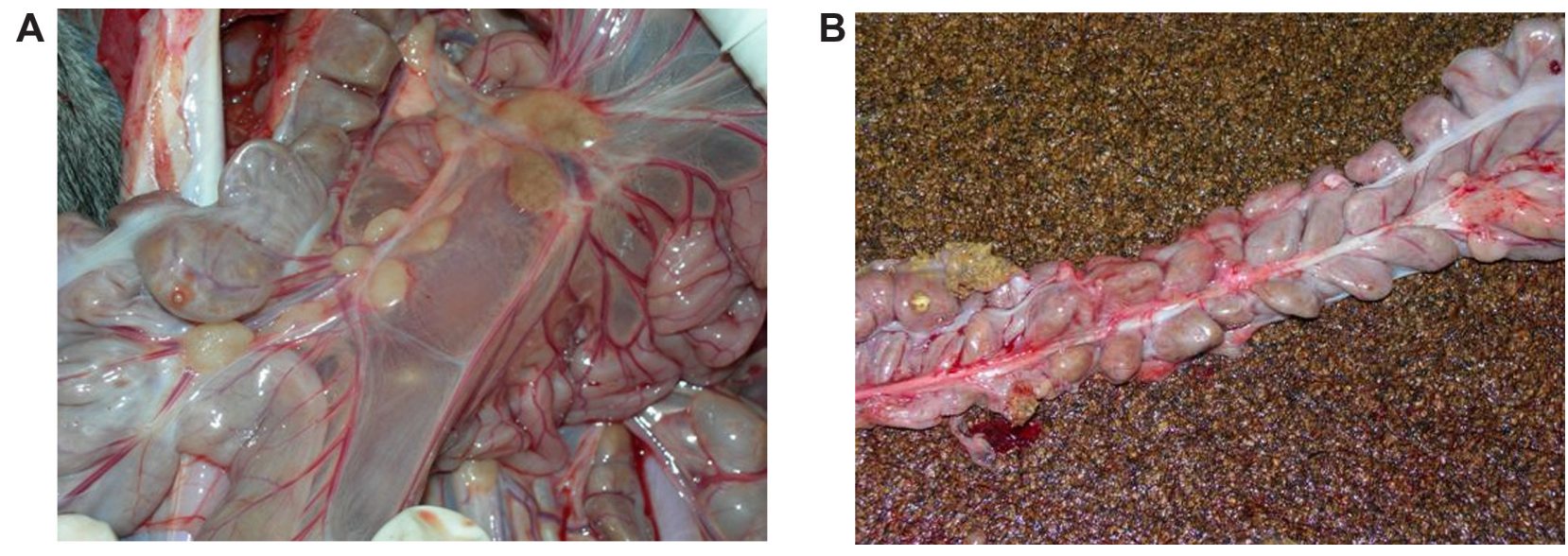

Figure I Gross pathological findings in male adult African green monkeys with experimental Cyclospora infections showing (A) enlarged mesenteric lymph nodes and (B) extensive hemorrhages observed in the intestines.

through ascending concentrations of absolute isopropyl alcohol starting from $80 \%$ to $100 \%$. The tissues were cleared in xylene, embedded in paraffin wax, mounted on blocks of wooden chunks, and fixed on the microtome. The tissues in paraffin wax blocks were sectioned into $5 \mu \mathrm{m}$-thick pieces. Four sections were made from every block specimen. These tissue sections were then dewaxed in xylene and hydrated through graded alcohol $(100 \%$ to $50 \%)$, cleared in xylene and alcohol, and washed in water. The tissues were then mounted on microscope slides stained with hematoxylin and eosin before being sealed using destrene 80 , dibutyl phthalate, and a xylene (DPX) mountant. ${ }^{34,35}$ The sections were examined under a light microscope at $100 \times, 400 \times$, and $1000 \times$ magnification using a discussion microscope (Leitz Laborlux 12; Leitz, Wetzlar, Germany). The results were recorded and, where necessary, photomicrographs were taken using a digital camera (Sony CyberShot 8.1-megapixel camera; Sony Corporation, Tokyo, Japan).

All of the experimental work on the study animals was carried out humanely according to international standards as governed by the Institutional Review Committee and the Animal Care and Animal Use Committee of the Institute of Primate Research.

\section{Results}

The two female juvenile and two male adult AGMs with experimental Cyclospora infections were humanely sacrificed 49 days post-inoculation. On gross examination, the two juvenile female monkeys had very few abnormalities. The carcasses were thin, with empty stomachs and slight weight gain, and one animal had slightly enlarged mesenteric lymph nodes (Table 1 and Figure 1A). The male adults displayed more pathology,

Table 2 Histopathological findings in the four Cercopithecus aethiops (African green monkeys) with experimental Cyclospora infections studied at the Institute of Primate Research

\begin{tabular}{|c|c|c|c|c|}
\hline AnimID & Stomach & Intestines & Lymph nodes & Liver \\
\hline Ver $1974 \mathrm{~F} / \mathrm{J}$ & $\begin{array}{l}\text { Mucous membrane } \\
\text { entire, capillaries filled } \\
\text { with blood_congested }\end{array}$ & $\begin{array}{l}\text { Congestion of the blood } \\
\text { vessels, reactive mitotic } \\
\text { activity at the crypts }\end{array}$ & $\begin{array}{l}\text { Hyperplasia, loss of lymph } \\
\text { node structure, proliferation } \\
\text { of lymphocytes with many } \\
\text { reactive follicles }\end{array}$ & $\begin{array}{l}\text { Lymphocytic infiltration of the } \\
\text { periportal area, single cell necrosis, } \\
\text { no clear demarcation of hepatocytes } \\
\text { and lobules, degeneration of liver cells }\end{array}$ \\
\hline Ver 2009 F/J & No observable defects & $\begin{array}{l}\text { Many goblet cells } \\
\text { on border, increased } \\
\text { mitotic activity }\end{array}$ & No observable defects & Mild degenerative changes \\
\hline Ver 2065 M/A & $\begin{array}{l}\text { Disruption of the } \\
\text { mucosal layer, parasites } \\
\text { in the deep crypts }\end{array}$ & $\begin{array}{l}\text { Burst and bloated } \\
\text { epithelial border, } \\
\text { parasites in enterocytes }\end{array}$ & $\begin{array}{l}\text { Extensive hyperplasia with } \\
\text { many mitotic cells }\end{array}$ & Few granulomas \\
\hline Ver 2092 M/A & $\begin{array}{l}\text { Disruption of mucosal } \\
\text { layer }\end{array}$ & $\begin{array}{l}\text { Intact intestinal borders, } \\
\text { intense lymphocytic } \\
\text { infiltration, parasites } \\
\text { in the enterocytes }\end{array}$ & $\begin{array}{l}\text { Area with congestion and } \\
\text { loss of structural detail }\end{array}$ & $\begin{array}{l}\text { Granulomas-numerous and } \\
\text { at different stages of development, } \\
\text { heterophils in the blood vessels and, } \\
\text { hemosiderin deposits }\end{array}$ \\
\hline
\end{tabular}

Abbreviations: AnimID, animal identification number of the four experimental Cyclospora-inoculated study animals, comprised of two female juvenile and two male adult African green monkeys; Ver, Vervet monkey; F, female; M, male; A, adult; J, juvenile. 
A

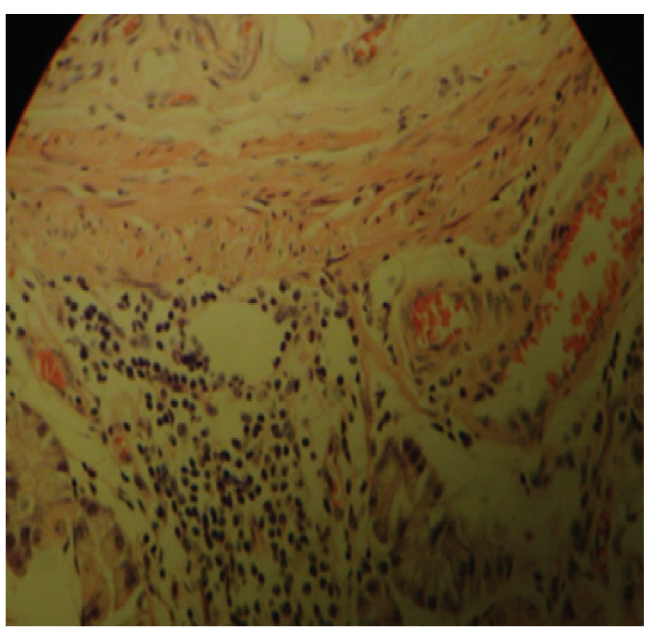

C

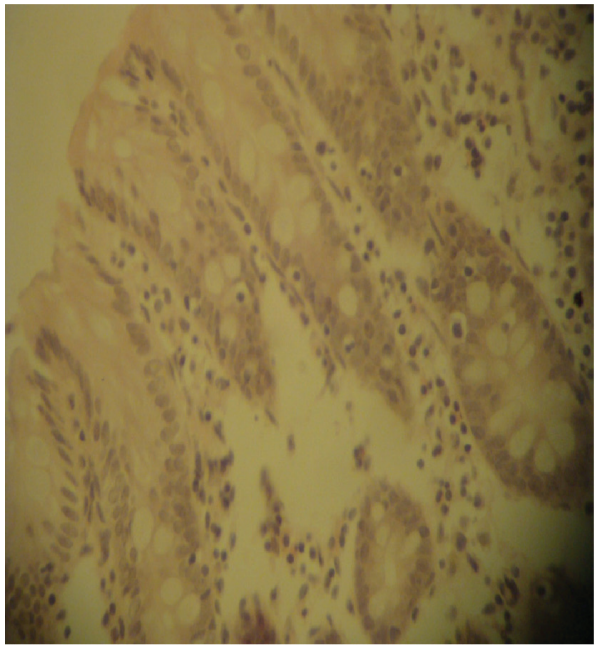

B

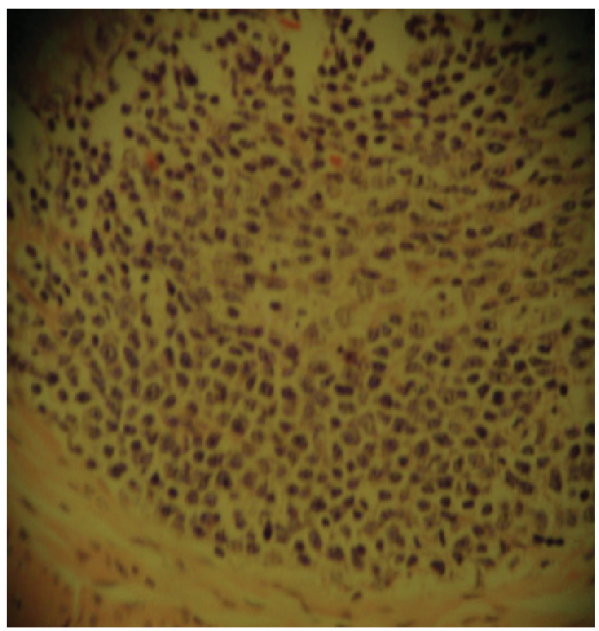

D

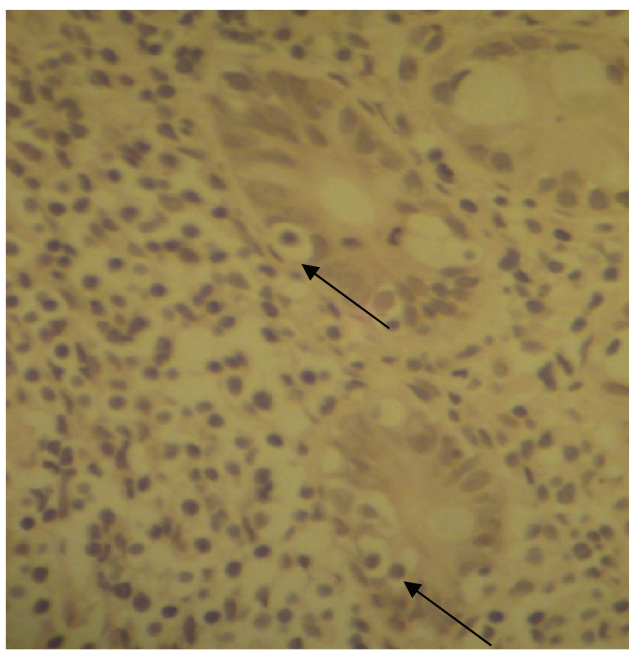

Figure 2 Stomach mucosae of African green monkeys with experimental Cyclospora infection showing (A) intensive lymphocytic infiltration and congested capillaries (H\&E stain, 400×), (B) intensive lymphocytic infiltration (H\&E stain, 400×), (C) mild lymphocytic infiltration and many goblet cells (H\&E stain, 400×), and (D) mild lymphocytic infiltration and parasite vacuoles in the enterocytes (arrow, H\&E stain, 400X).

Abbreviation: H\&E, hematoxylin and eosin.
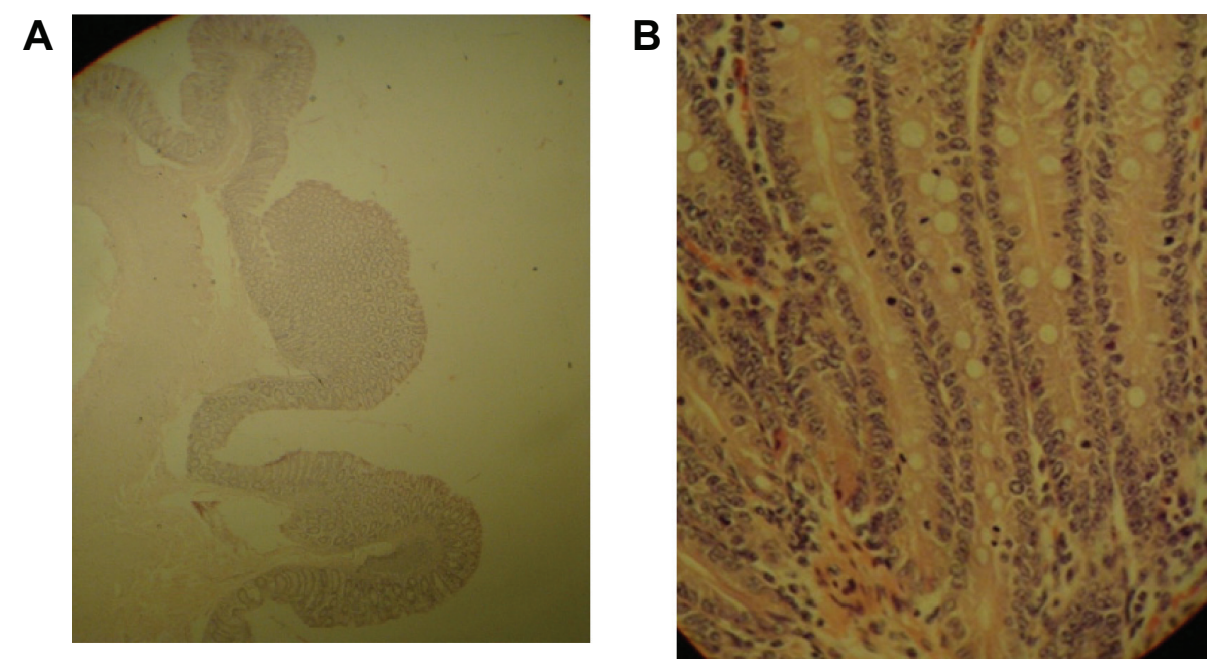

Figure 3 Intestinal mucosae of African green monkeys with experimental Cyclospora infection showing (A) intense lymphocytic infiltration with intact borders (H\&E stain, I00X) and (B) mild lymphocytic infiltration and parasite vacuoles in the enterocytes (arrow) and many goblet cells (H\&E stain, 400X).

Abbreviation: H\&E, hematoxylin and eosin. 
with hemorrhagic mucosal surfaces of the stomach and enlarged mesenteric lymph nodes (Table 1 and Figure 1A and B). Hemorrhages were spread to the small and large intestines (Figure 1B). The liver showed widespread, mild surface pitting, with moderate focal necrotic foci of about $1 \mathrm{~mm}$ in diameter spread all over the surface. One of the male adult monkeys had a congested and enlarged spleen.
In general, upon microscopic examination of the hematoxylin and eosin-stained tissue sections, significant histopathological findings were observed in both the female juvenile and adult male AGMs examined. The lesions ranged from mild inflammatory reactions of the stomach and intestinal walls to disruptions of the mucosal layer to intense cellular infiltration with mitotic activity (Table 2 and Figures 2-5).

\section{A}
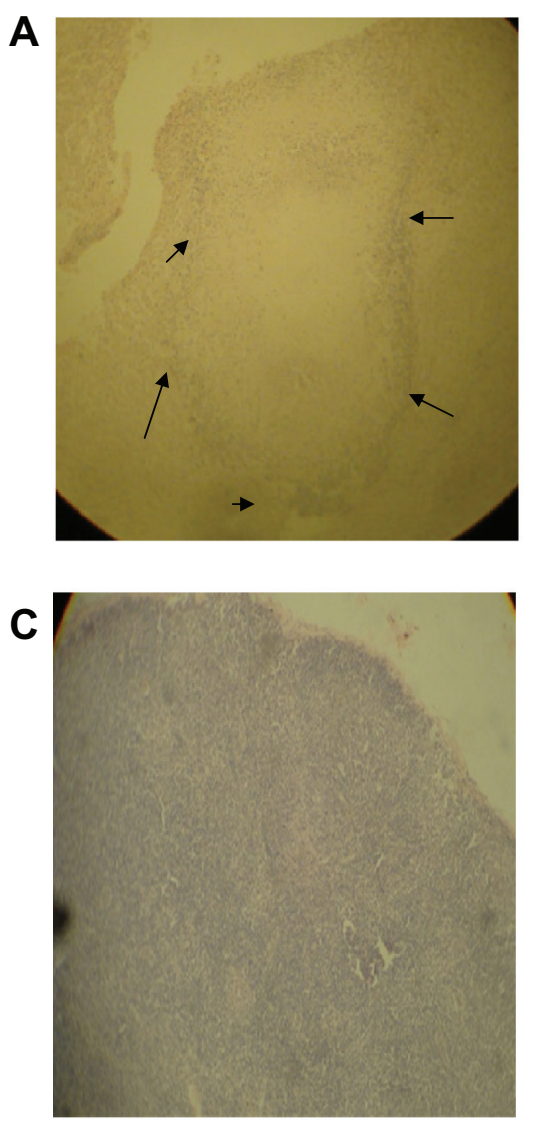

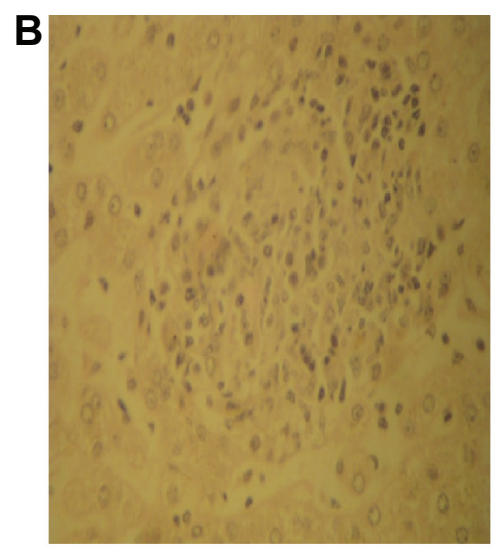

D

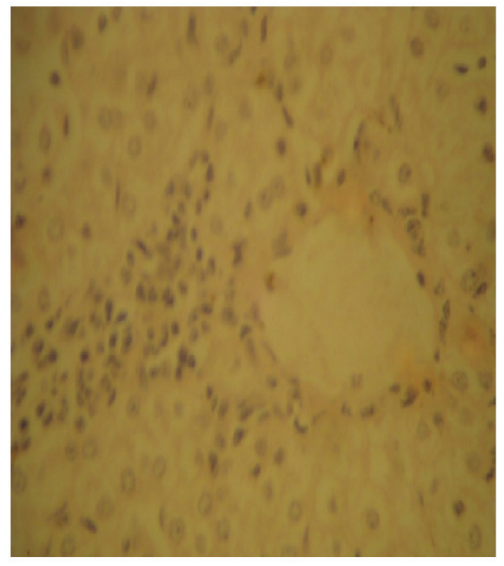

E

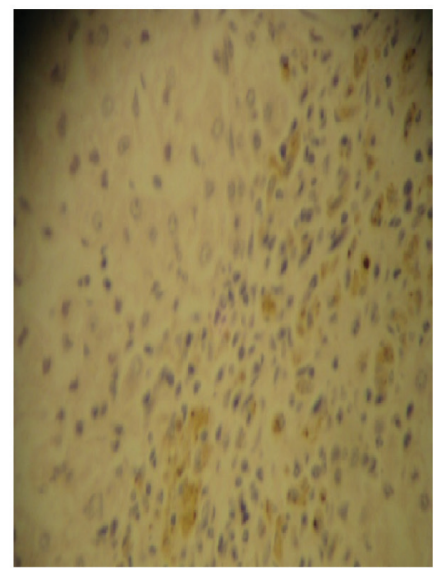

Figure 4 Liver sections of African green monkeys with experimental Cyclospora infection showing (A) the beginning of granuloma formation (H\&E stain, I00 $\times$ ), (B) the beginning of granuloma formation (H\&E stain, 400×), (C) mature granuloma formation (H\&E stain, I00×), (D) mild periportal lymphocytic infiltration (H\&E stain, 400×), and (E) diffuse mild lymphocytic infiltration and loss of hepatocyte structure and hemosiderin deposits (H\&E stain, 400X).

Abbreviation: H\&E, hematoxylin and eosin. 


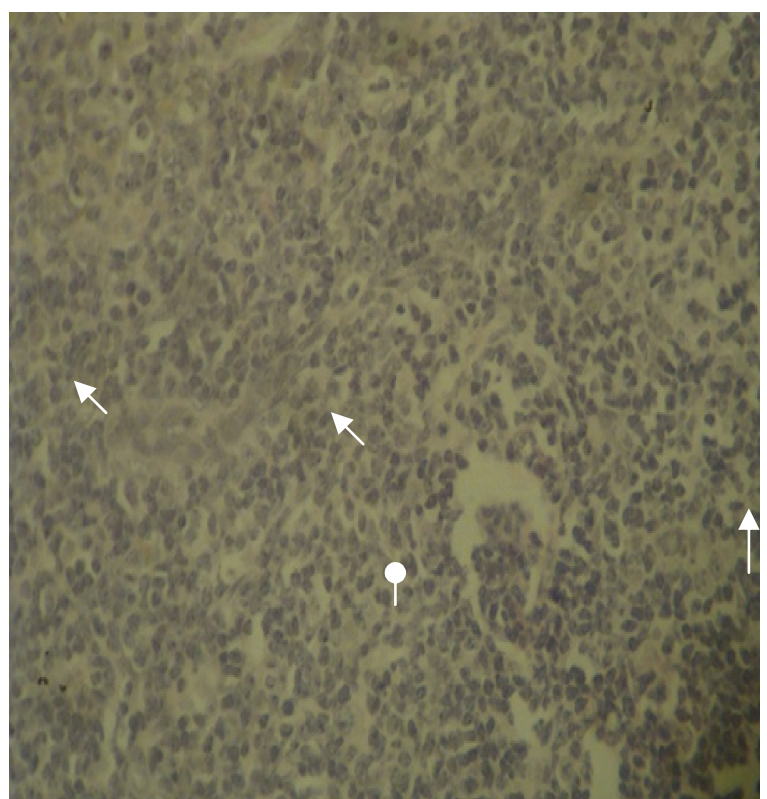

Figure 5 Mesenteric lymph node section of African green monkeys with experimental Cyclospora infection showing uniform intense lymphocytic proliferation with loss of lymph node structure (H\&E stain, 400x).

Abbreviation: H\&E, hematoxylin and eosin.

Figure 2 shows the stomach mucosae of the AGMs with experimental Cyclospora infections showing varying pathology. Figure 2A and B showed stomach walls with intense lymphocytic infiltration and congested blood vessels, while Figure 2C and D showed some sections of the stomach wall with mild lymphocytic infiltration and increased goblet cells. The lymphocyte cells that infiltrated the stomach walls were of different sizes and varying intensities. Parasite vacuoles were observed in the cells (Figure 2D).

Upon histopathology, the intestines presented an intact intestinal border with intense cellular infiltration (Figure 3A). On higher magnification, the intestinal wall showed intense lymphocytic infiltration, increased goblet cells, and parasites in the enterocytes (Figure 3B).

The livers had numerous granulomas at different stages of development; the granulomas started at the portal triad and extended into the liver tissue (Figure 4A). The granulomas begun as small aggregates of cells that displaced the hepatocytes and progressed to mature granulomas, with complete destruction of hepatocytes and no clear demarcation of the liver lobules (Figure 4A to C). Mild lymphocytic infiltration was observed around the periportal area and in the interlobular connective tissues (Figure 4D). In some sections of the liver, the diffuse mild lymphocytic infiltration caused a loss of hepatocyte structure and hemosiderin deposits (Figure 4E).

The mesenteric lymph nodes displayed varying pathology, from mild to intense proliferation of lymphocytes. Lymph node tissue sections from male adults presented intense lymphocytic proliferation, which resulted in the destruction of lymph node structures (Figure 5).

\section{Discussion}

The experimentally Cyclospora-infected AGMs were asymptomatic throughout the 7-week study period, as reported by other authors with natural infections. ${ }^{19,21}$

Upon gross postmortem evaluation of AGMs with experimental Cyclospora infections, few changes were observed in female juveniles, with male adults displaying more pathology. These findings indicate that the juvenile nonhuman primates were more resistant to Cyclospora infection even though the infectious dose was the same. However, histopathology confirmed infections in both age groups. Other authors have reported that Cyclospora infections are widespread in nonhuman primates, based on fecal examination for Cyclospora oocysts even in asymptomatic monkeys. ${ }^{19-22,36}$ Grossly, the moderate hemorrhagic mucosa of the stomach observed in the study animals compares well to lesions described on the distal duodenum in human patients. ${ }^{24}$ The enlarged lymph nodes denote a reactive proliferation of lymphocyte cells, which is common in infections. The pitting lesions on the liver surface were the locations of the granulomas as confirmed by histopathology.

Significant histopathological findings were observed in the stomachs, intestines, livers, and lymph nodes. The findings on the stomach and intestinal mucosa of inflammatory reactions with mild to intense lymphocytic infiltration and parasitophorous vacuoles in the enterocytes are similar to the findings described by authors of studies on duodenal and jejunal aspirates of human patients with Cyclospora infections. ${ }^{24,25,37,38}$ The finding of periportal and diffuse lymphocytic infiltration and development of granulomas in the liver confirms extraintestinal involvement of Cyclospora infections. The pattern of the granulomas starting around the hepatic triad suggested a spreading of the infectious agent from the intestine through the portal system.

Previous efforts by other authors to establish $C$. cayetanensis in laboratory animals and even in healthy human volunteers have been disappointing, ${ }^{15,39}$ with infection failing to establish, which meant we were unable to effectively study the disease process. The present study, which utilized nonhuman primates and nonhuman-derived Cyclospora oocysts, yielded important methodology, data, and descriptions of gross and histopathological findings in Cyclospora infections. 


\section{Conclusion}

The association of Cyclospora infection with gastrointestinal and extraintestinal pathology has been described in Cercopithecus aethiops in Kenya in this study. The postmortem findings in African green monkeys with experimental Cyclospora infections ranged from mild inflammatory reactions in the stomach and intestinal walls to intense cellular infiltrations. The livers had numerous granulomas, periportal and diffuse cellular infiltrations with a loss of hepatocyte structure. The mesenteric lymph nodes were enlarged, with varying proliferation of the lymphocytes. These results were similar to histopathological findings described for humans with cyclosporiasis. On the basis of these results, the AGM may be used to study further aspects of cyclosporiasis that may not be possible to study in humans due to ethical reasons.

\section{Acknowledgments}

The authors wish to acknowledge the technical assistance given by staff members of the Animal Science Department, IPR, and Histopathology Laboratory of the University of Nairobi.

\section{Disclosure}

The authors declare no conflicts of interest in this work.

\section{References}

1. Herwaldt BL, Ackers ML. An outbreak in 1996 of cyclosporiasis associated with imported raspberries Cyclospora Working Group. N Engl J Med. 1997;336(22):1548-1556.

2. Centers for Disease Control and Prevention. Outbreaks of cyclosporiasis - United States, 1997. MMWR Morb Mortal Wkly Rep. 1997;46:451-452.

3. Alakpa GE, Fagbenro-Beyiouku AF. Cyclospora cayetanensis and intestinal parasitic profile in stool samples in Lagos, Nigeria. Acta Protozool. 2002;41:221-227.

4. Bern C, Ortega Y, Checkley W, et al. Epidemiological differences between cyclosporiasis and cryptosporidiosis in Peruvian children. Emerg Infect Dis. 2002;8(6):581-585.

5. Kumar SS, Ananthan S, Saravanan P. Role of coccidian parasites in causation of diarrhoea in HIV infected patients in Chennai. Indian J Med Res. 2002;116:85-89.

6. Karanja RM, Gatei W, Wamae N. Cyclosporiasis: an emerging public health concern around the world and in Africa. Afr Health Sci. 2007;7(2):62-67.

7. Berlin OG, Novak SM, Porschen RK, Long EG, Stelma GN, Schaeffer FW 3rd. Recovery of Cyclospora organisms from patients with prolonged diarrhoea. Clin Infect Dis. 1994;18(4):606-609.

8. Centers for Disease Control and Prevention. Update: outbreaks of Cyclospora cayetanensis infection - United States and Canada, 1996. MMWR Morb Mortal Wkly Rep. 1996;45(28):611-612.

9. Pape JW, Verdier RI, Boncy M, Boncy J, Johnson WD Jr. Cyclospora infection in adults infected with HIV. Clinical manifestations, treatment, and prophylaxis. Ann Intern Med. 1994;121(9):654-657.

10. Ashford RW. Occurrence of an undescribed coccidian in man in Papua New Guinea. Ann Trop Med Parasitol. 1979;73(5):497-500.
11. Ortega YR, Gilman RH, Sterling CR. A new coccidian parasite (Apicomplexa: Eimeriidae) from humans. J Parasitol. 1994;80(4): 625-629.

12. Nassef NE, el-Ahl SA, el-Shafee OK, Nawar M. Cyclospora: a newly identified protozoan pathogen of man. J Egypt Soc Parasitol. 1998;28(1):213-219.

13. Bern C, Hernandez B, Lopez MB, et al. Epidemiologic studies of Cyclospora cayetanensis in Guatemala. Emerg Infect Dis. 1999;5(6): 766-774.

14. Eberhard ML, Nace EK, Freeman AR, Streit TG, da Silva AJ, Lammie PJ. Cyclospora cayetanensis infections in Haiti: a common occurrence in the absence of watery diarrhea. Am J Trop Med Hyg. 1999;60(4):584-586.

15. Eberhard ML, Ortega YR, Hanes DE, et al. Attempts to establish experimental Cyclospora cayetanensis infection in laboratory animals. J Parasitol. 2000;86(3):577-582.

16. Chu DM, Sherchand JB, Cross JH, Orlandi PA. Detection of Cyclospora cayetanensis in animal fecal isolates from Nepal using an FTA filter-base polymerase chain reaction method. Am J Trop Med Hyg. 2004;71(4):373-379.

17. García-López HL, Rodríguez-Tovar LE, Medina-De la Garza CE. Identification of Cyclospora in poultry. Emerg Infect Dis. 1996;2(4): 356-357.

18. Abbassa ET, Rahemo ZIF. First record of Cyclospora cayetanensis (Protozoa: Apicomplexa) with some notes on its occurrence in buffalos from Neinava governorate, Iraq. 2006. Available from: http:/www. docstoc.com/doc/34282247/source. Accessed 29 March, 2012.

19. Smith HV, Paton CA, Girdwood RW, Mtambo MM. Cyclospora in nonhuman primates in Gombe, Tanzania. Vet Rec. 1996;138(21):528.

20. Legesse M, Erko B. Zoonotic intestinal parasites in Papio anubis (baboon) and Cercopithecus aethiops (vervet) from four localities in Ethiopia. Acta Trop. 2004;90(3):231-236.

21. Eberhard ML, Njenga MN, DaSilva AJ, et al. A survey for Cyclospora spp. in Kenyan primates, with some notes on its biology. J Parasitol. 2001;87(6):1394-1397.

22. Ekanayake DK, Arulkanthan A, Horadagoda NU, et al. Prevalence of Cryptosporidium and other enteric parasites among wild non-human primates in Polonnaruwa, Sri Lanka. Am J Trop Med Hyg. 2006;74(2): 322-329.

23. Orihel TC, Ash LR. Intestinal protozoa. In: Parasites in Human Tissues, 1st ed. Chicago, IL: American Society of Clinical Pathologists; 1995:28-31.

24. Connor BA, Shlim DR, Scholes JV, Rayburn JL, Reidy J, Rajah R. Pathologic changes in the small bowel in nine patients with diarrhea associated with a coccidia-like body. Ann Intern Med. 1993;119(5):377-382.

25. Ortega YR, Nagle R, Gilman RH, et al. Pathologic and clinical findings in patients with cyclosporiasis and a description of intracellular lifecycle stages. J Infect Dis. 1997;176(6):1584-1589.

26. Shoff WH, Behrman AJ, Shepherd SM. Cyclospora. Medscape Reference [serial on the internet]. Updated 2010 Feb. Available from: http://emedicine.medscape.com/refarticle-srch/236105-overview. Accessed November 26, 2007.

27. Zar FA, El-Bayoumi E, Yungbluth MM. Histologic proof of acalculous cholecystitis due to Cyclospora cayetanensis. Clin Infect Dis. 2001;33(12):E140-E141.

28. Sifuentes-Osornio J, Porras-Cortés G, Bendall RP, Morales-Villarreal F, Reyes-Terán G, Ruiz-Palacios GM. Cyclospora cayetanensis infection in patients with and without AIDS: biliary disease as another clinical manifestation. Clin Infect Dis. 1995;21(5):1092-1097.

29. Richardson RF Jr, Remler BF, Katirji B, Murad MH. Guillain-Barre syndrome after Cyclospora infection. Muscle Nerve. 1998;21(5):699-671.

30. Connor BA, Johnson EJ, Soave R. Reiter syndrome following protracted symptoms of Cyclospora infection. Emerg Infect Dis. 2001;7(3):453-454.

31. Di Glullo AB, Cribari MS, Bava AJ, Cicconetti JS, Collazos R. Cyclospora cayetanensis in sputum and stool samples. Rev Inst Med Trop Sao Paulo. 2000;42(2):115-117. 
32. Hussein EM, Abdul-Manaem AH, el-Attary SL. Cyclospora cayetanensis oocysts in sputum of a patient with active pulmonary tuberculosis, case report in Ismailia, Egypt. $J$ Egypt Soc Parasitol. 2005;35(3):787-793.

33. Cheesbrough M. District Laboratory Practice in Tropical Countries Part 1, 2nd ed. New York, NY: Cambridge University Press; 2005.

34. Armed Forces Institute of Pathology (US). Manual of the Histzological Staining Methods of the Armed Forces Institute of Pathology, 3rd ed. In: Luna LG, editor. New York, NY: McGraw Hill; 1968.

35. Leeson CR, Leeson TS, Paparo AA. Preparation of tissues for histology. In: Textbook of Histology, 5th ed. Philadelphia, PA: WB Saunders Co; 1985:7-13.

36. Eberhard ML, da Silva AJ, Lilley BG, Pieniazek NJ. Morphologic and molecular characterization of new Cyclospora species from Ethiopian monkeys: C. cercopitheci sp.n., C. colobi sp.n., and C. papionis sp.n. Emerg Infect Dis. 1999;5(5):651-658.
37. Nhieu JT, Nin F, Fleury-Feith J, Chaumette MT, Shaeffer A, Bretagne $\mathrm{S}$. Identification of intracellular stages of Cyclospora species by light microscopy of thick sections using hematoxylin. Hum Pathol. 1996;27(10):1107-1109.

38. Pingée-Suttor V, Douglas C, Wettstein A. Cyclospora infection masquerading as coeliac disease. Med J Aust. 2004;180(6):295-296.

39. Alfano-Sobsey EM, Eberhard ML, Seed JR, et al. Human challenge pilot study with Cyclospora cayetanensis. Emerg Infect Dis. 2004; 10(4):726-728.

\section{Publish your work in this journal}

Pathology and Laboratory Medicine International is a peer-reviewed, open access journal focusing on innovative basic research and translational research related to pathology or human disease. The journal includes original research, updates, case reports, reviews and commentaries on current controversies. The Academic Sponsor of this journal is the Chinese American Pathology Association (CAPA). The manuscript management system is completely online and includes a very quick and fair peer-review system. Visit http://www.dovepress.com/testimonials.php to read real quotes from published authors.

Submit your manuscript here: http://www.dovepress.com/pathology-and-laboratory-medicine-international-journal 